\title{
Analysis of spatial-temporal and ion characteristics change of precipitation in the Southwest of China, from policy perspective
}

\author{
Luo Y.H. ${ }^{1}$, Wu L.J. ${ }^{2}$, Xiao Y.N. ${ }^{2}$ and He R.J. ${ }^{3 *}$ \\ ${ }^{1}$ School of Basic Medical, Southwest Medical University, Luzhou 646000, China \\ 'Luzhou Environmental Monitoring Center, Luzhou 646000, China \\ ${ }^{3}$ Department of Environmental and Industrial Hygiene, College of Public Health, Southwest Medical University, Luzhou, 646000, Sichuan, \\ China \\ Received: 26/03/2020, Accepted: 06/04/2020, Available online: 16/04/2020 \\ *to whom all correspondence should be addressed: e-mail: herenjiang@163.com
} https://doi.org/10.30955/gnj.003315

\section{Graphical abstract}
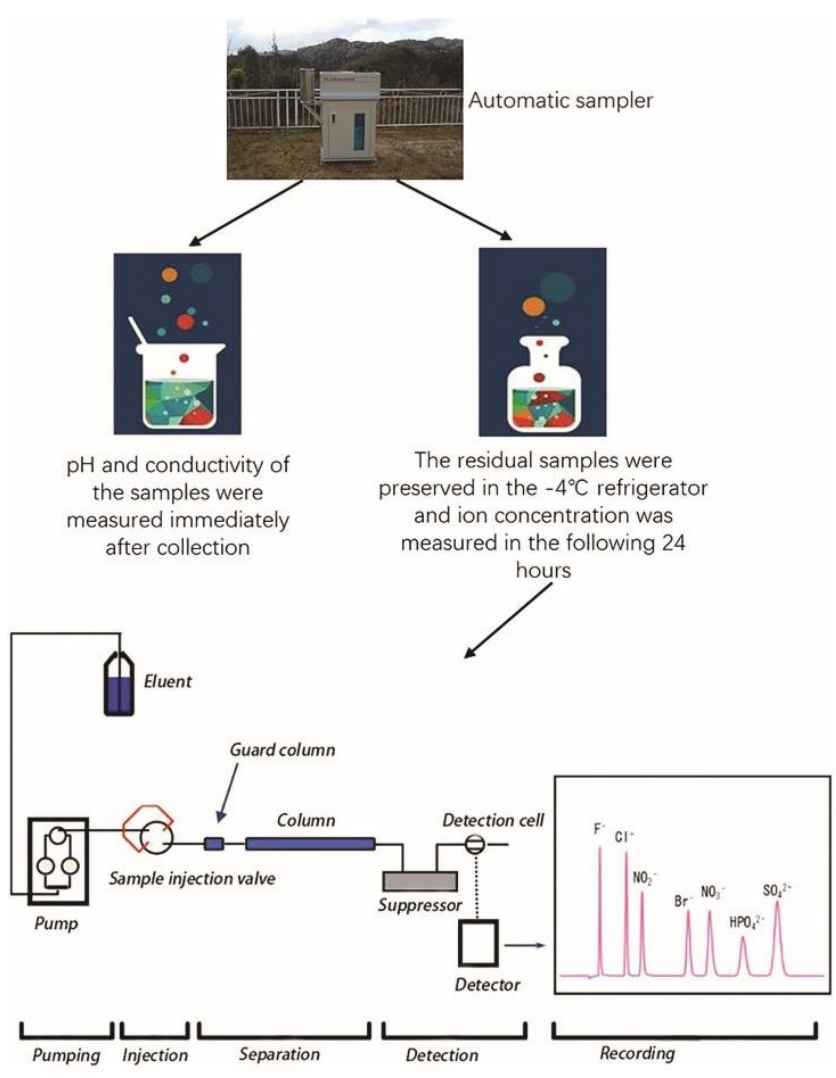

Abstract

According to the data from Luzhou environmental monitoring center from 2015 to 2018, the tendency of spatial-temporal and ion characteristics in precipitation have been analyzed in order to demonstrate the precipitation pollution status. Traditionally, the environment may become worse as the development of the economy, especially in the developing countries. However, the results show that the quality of precipitation has been improved during these four years. The annual average $\mathrm{pH}$ value of precipitation in Luzhou City increased, and the frequency and conductivity of acid rain declined, which indicates that the quality of precipitation improved annually. This may due to a strictly political strategy enacting. The decrease of the equivalent concentration ratio of $\mathrm{SO}_{4}{ }^{2-}$ and $\mathrm{NO}_{3}{ }^{-}$demonstrated the transformation of pollution type, evolving from a typical sulfuric acid to a mixed type of sulfuric and nitric acid, indicating the economic transformation. The correlation coefficient between $\mathrm{SO}_{4}{ }^{2-}$ and $\mathrm{NO}_{3}{ }^{-}$was high. This may be because $\mathrm{SO}_{2}$ and $\mathrm{NO}_{2}$ emitted from industrial enterprises entered the atmosphere together in the same way. The strong correlation between $\mathrm{F}^{-}$and $\mathrm{SO}_{4}{ }^{2-}, \mathrm{NO}_{3}{ }^{-}$may relate the pollution sources such as cement and glass enterprises. It is necessarily to strengthen the management of relative enterprises.

Keywords: $\mathrm{pH}$, precipitation, ion characteristics.

\section{Introduction}

Air pollution has been a universal concern in many countries because of its harmful impacts on public health, ecosystem, and economy. The substances of air pollution contain sulfur dioxide $\left(\mathrm{SO}_{2}\right)$, nitrogen oxides ( $\mathrm{NOx}$ ), excessive carbon dioxide $\left(\mathrm{CO}_{2}\right)$, Volatile Organic Compounds (VOCs), particulates (PM2.5, PM10), etc. (Siddiqi and Farsi, 2019). These emissions are released to the atmosphere either by natural processes or human activities (US EPA, 2017a). Air pollutants lead numerous of environmental problems such as acid rain, climate changes, crop and forest damage and adverse impacts on wildlife. The effect of this pollution costs approximately $\$ 5$ trillion per year to cure people and repair the environmental damage (World Bank, 2016). Therefore, more works along with governments and environmental agencies to decrease air pollution and damage it causes are needed.

One the environmental consequences of air pollution is atmospheric acid deposition including dry deposition and wet deposition. Precipitation is often recognized as wet deposition (Grimm and Lynch, 2004). Its acidity can be expressed as the magnitude of solution acidity $\left(\mathrm{H}^{+}\right.$ concentration or $\mathrm{pH}$ ). When the $\mathrm{pH}$ of precipitation is lower than 5.6, the precipitation is often renamed acid 
rain/precipitation which is one of the global environmental problems (Galloway et al., 1976). The performance of $\mathrm{pH}$ and other chemical parameters of precipitation has been monitored for many years to ensure the quality of precipitation. From such monitoring activities, data are evident for determining temporal and spatial deposition trend, predicting ecological effects, modeling atmospheric processes, or planning future emission control strategies (Wisniewski and Kinsman, 1988).

The significant chemical factors in acid rain are nitrate and sulfate because $\mathrm{NO}_{x}$ and $\mathrm{SO}_{2}$ exhausted from mobile and stationary sources mainly lead to a decrease of the rain acidity by chemical reactions (Wakida et al., 2001). Lightning and volcanic eruptions react with water molecules or get mixed with dust are typical natural processes to form these two chemical compounds. These molecules terminally fall as dry or wet deposition (Mutahharah et al., 2014). NOx and $\mathrm{SO}_{2}$ as precursors of acid rain may cause secondary pollutants like particles and nitrogen species (Menz and Seip, 2004).

Acid rain predominates many countries such as the Canada, United States, China, and Europe (Bowman, 1992). Although many researchers analyzed the characteristics of acid rain all over the world, there is limited literature addressing acid rain in China, especially in these highly developmental economic periods. This essay analyzed the data of the spatial-temporal and ion characteristics of precipitation in the recent four years in Luzhou city. The acidity of precipitation in this city was extremely serious. We hope this article would help to provide useful information about the quantity variation of ion characteristics and evaluate the quality of the atmosphere in Luzhou city.

\section{Sampling site}

Luzhou, $\mathrm{N} 28^{\circ} 52^{\prime} 28.94^{\prime \prime}, \mathrm{E} 105^{\circ} 26^{\prime} 20.32^{\prime \prime}$, is situated in the southwest of China. Geomorphologically, it is dominated by medium mountains (1000-1902 $\mathrm{m}$ above the sea level) and low mountains (500-1000 $\mathrm{m}$ above sea level). There are four distinct seasons in Luzhou because of its typical continental monsoon climate. According to Luzhou people's government data, the temperature and rainfall are relatively higher in Luzhou compared with surrounding cities. Rainfall mainly focused from July to August and the least concentrated from December to March next year.

By the end of 2017, Luzhou Economic and Social Development Statistic Bulletin presented that the population of the city has exceeded 5 million, and Gross Domestic Product was 159.6 billion RMB, and the contribution of the three industries to the growth of the economy was $5.0 \%, 59.7 \%$, and $35.3 \%$ respectively. The second and third industries are still pillar industries.

\section{Methods}

The samples were collected with $500 \mathrm{ml}$ polyethylene bottles. They had been cleaned with hydrogen chloride (2$3 \mathrm{~mol} / \mathrm{L})$ and rinsed with Milli-Q water (18.25 M $\Omega$ ) before use (Hua and Han, 2011). The bottles were located in the automatic sampler that immediately collected the sample when it was rain. The samplers were situated on the roofs $1.5 \mathrm{~m}$ high above the ground, gathering 24 hours wet precipitation from 8 a.m. to 8 a.m. the next day as one sample to analyze, and 247 samples were collected.

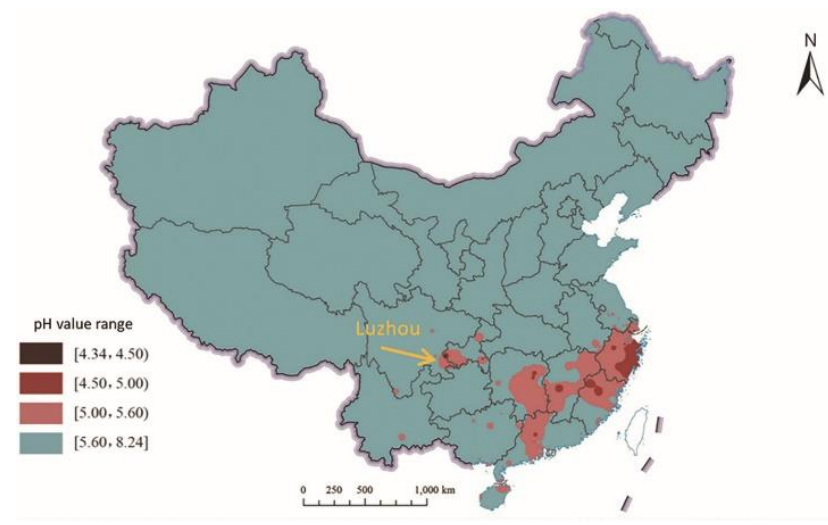

Figure 1. The location of Luzhou City and the distribution of acid rain in 2018 in China (according to Environmental Protection Administration of China).

We analyzed $\mathrm{pH}$ and conductivity of the samples immediately after collection. Then the residual samples were preserved in the $-4{ }^{\circ} \mathrm{C}$ refrigerator and ion concentration was measured in the following 24 hours after sampling. $0.45 \mu \mathrm{m}$ organic Millipore membrane was used to filtrate samples and then immersed by deionized water for 24 hours (Shi et al., 2013). This membrane is an inert material with features of Uniform aperture, fast rate passing and avoiding from the absorption with other chemical factors in the sample. Therefore, the samples were able to prevent loss and contamination of components to be tested (Figure 1).

Major anions $\left(\mathrm{Cl}^{-}, \mathrm{F}^{-}, \mathrm{SO}_{4}{ }^{2-}, \mathrm{NO}_{3}{ }^{-}\right)$were demonstrated by an ionic chromatography (ICS-1500, 09090451). The detection limits of $\mathrm{F}^{-}, \mathrm{Cl}^{-}, \mathrm{NO}_{3}{ }^{-}, \mathrm{SO}_{4}{ }^{2-}$ were $0.03,0.03$, 0.1 and $0.1 \mathrm{mg} / \mathrm{L}$. Major cations $\left(\mathrm{K}^{+}, \mathrm{Na}^{+}, \mathrm{Mg}^{2+}, \mathrm{Ca}^{2+}, \mathrm{NH}_{4}{ }^{+}\right)$ were measured by ionic chromatography (ICS-90, 7100483). The detection limits of $\mathrm{K}^{+}, \mathrm{Na}^{+}, \mathrm{Mg}^{2+}, \mathrm{Ca}^{2+}, \mathrm{NH}_{4}^{+}$ were $0.01,0.01,0.01,0.03$ and $0.01 \mathrm{mg} / \mathrm{L}$. Reagent and procedural blanks were measured in parallel to the sample treatment and the blanks were below the detection limit of the measured species. The relative standard deviations (RSD\%) of the method were below 5\%. Quantitative recoveries of spiked samples ranged from $85 \%$ to $120 \%$.

\section{Results and discussion}

\section{1. $\mathrm{pH}$ value, frequency of acid rain and conductivity}

From the previous studies, $\mathrm{CO}_{2}, \mathrm{NO}_{x}$, and $\mathrm{SO}_{2}$ existing in the nature can dissolve into the clouds and droplets, causing $\mathrm{pH}$ values of the rain in the clean atmosphere to be between 5.0-5.6 (Charlson and Rodhe, 1982), (Galloway et al., 1993). Precipitation with $\mathrm{pH}$ below 5.0 results from the presence of natural or anthropogenic emission of $\mathrm{H}_{2} \mathrm{SO}_{4}$ and/or $\mathrm{HNO}_{3}$, while that of above 6.0 might consider certain inputs of alkaline species into the precipitation. It is shown in Table 1. 247 rain samples were collected from 2015 to 2018. The average $\mathrm{pH}$ value observed in Luzhou city 
increased from 4.28 in 2015 to 5.00 in 2018. Total rainfall is above $1000 \mathrm{~mm}$. The acid rainfall did not show significant difference from 2015 to 2017, however, it was observed obvious decrease in $2108(P<0.05)$. Both maximum and minimum $\mathrm{pH}$ values of precipitation were observed in 2016.

Frequency of acid rain represents the intensity of acidity of precipitation. It equals the ratio of the number of acid rains to the total number of rains, It is an important indicator to ensure whether the certain area is an acid rain area besides $\mathrm{pH}$ value (Siddiqi and Farsi, 2019). The frequency of acid rain observed a distinct decrease from $86 \%$ to $46 \%$ during the four years with consistency to the trend of $\mathrm{pH}$ value.
The conductivity of precipitation is considered to be a significant parameter in acid rain chemistry monitoring. The conductivity of ions in precipitation is generally used in the quality assessment on the analysis data of ionic components. Table 1 shows that the conductivity increased slightly in the first two years $(5.78$ to $6.20 \mathrm{mS} / \mathrm{m})$, then decreased obviously from 2016 to 2018 (6.20 to 3.67).

$\mathrm{pH}$ value calculating equation is as follows. $n$ indicates the number of rains. $V i$ indicates the $i$-th volume of rain.

$$
p H=-\log \frac{\sum_{i=1}^{n} 10^{-p H} \times V i}{\sum_{i=1}^{n} V i}
$$

Table 1. The statistical results of precipitation in Luzhou, 2015-2018

\begin{tabular}{ccccccccc}
\hline Years & $\begin{array}{c}\text { Number of } \\
\text { samples }\end{array}$ & $\begin{array}{c}\mathbf{p H} \text { mean } \\
\text { (in unit) }\end{array}$ & $\begin{array}{c}\text { Total rainfall } \\
(\mathbf{m m})\end{array}$ & $\begin{array}{c}\text { Acid rainfall } \\
(\mathbf{m m})\end{array}$ & $\begin{array}{c}\text { Frequency } \\
\text { of acid rain }\end{array}$ & $\begin{array}{c}\text { Max (in } \\
\text { unit) }\end{array}$ & $\begin{array}{c}\text { Min (in } \\
\text { unit) }\end{array}$ & $\begin{array}{c}\text { Conductivity } \\
\text { (ms/m) }\end{array}$ \\
\hline 2015 & 51 & 4.28 & 1091.70 & 853.50 & $86 \%$ & 6.64 & 3.25 & 5.78 \\
\hline 2016 & 59 & 4.43 & 1022.80 & 917.20 & $85 \%$ & 7.74 & 3.20 & 6.20 \\
\hline 2017 & 79 & 4.41 & 1084.40 & 877.00 & $69 \%$ & 6.74 & 3.55 & 4.67 \\
\hline 2018 & 58 & 5.00 & 1005.30 & 390.10 & $46 \%$ & 6.69 & 3.52 & 3.67 \\
\hline
\end{tabular}

Therefore, $\mathrm{pH}$ value, frequency of acid rain and conductivity all present that the quality of atmospheric precipitation is improving annually. $\mathrm{SO}_{2}$ and $\mathrm{NO}_{2}$ are the main acid-producing precursors of precipitation (Gao et al., 2001), (Lin et al., 1999). The main reason would be some relative policies enacted in this area. The government urged the enterprises with large pollutant emissions to enact strategy of "Total pollutant emission reduction" five years ago. According to the statistical data from Luzhou Environmental Protection of Agency, $\mathrm{SO}_{2}$ emissions decreased from 68,900 tons in 2014 to 36,900 tons in 2018. Meanwhile, $\mathrm{NO}_{2}$ emissions declined from 38,200 tons in 2014 to 24,400 tons in 2018.

\subsection{Ionic composition}

The equivalence ratio of the sum of anions to that of cations ( $\Sigma$ anions/ $\Sigma$ cations) is usually regarded as an indicator of the completeness of the measured major constituents (Al-Khashman, 2005). In this study, the mean equivalent sum of anions of that cations were between 0.92 and 0.96 , which suggested that all major ions were measured.

Table 2 shows that, in these four years, the concentration of each cation was all in the order of $\mathrm{NH}_{4}{ }^{+}>\mathrm{Ca}^{2+}>\mathrm{Mg}^{2+}>$ $\mathrm{Na}^{+}>\mathrm{K}^{+}$. The proportion of $\mathrm{NH}_{4}^{+}$and $\mathrm{Ca}^{2+}$ mass concentration ranged from $78.6 \%$ to $90.8 \%$ of the total amount of cations, indicating that the main cations of precipitation was $\mathrm{NH}_{4}{ }^{+}$and $\mathrm{Ca}^{2+}$. The order of mass concentration of each anion from high to low was: $\mathrm{SO}_{4}{ }^{2-}>$ $\mathrm{NO}_{3}{ }^{-}>\mathrm{Cl}^{-}>\mathrm{F}^{-}$, wherein the percentage of $\mathrm{SO}_{4}{ }^{2-}$ and $\mathrm{NO}_{3}{ }^{-}$ mass concentration ranged from $92.1 \%$ to $95.4 \%$ of the total anion, showing that $\mathrm{SO}_{4}{ }^{2-}$ and $\mathrm{NO}_{3}{ }^{-}$was the main anions of precipitation in Luzhou city.

Table 2. The ion concentration of precipitation in each year in Luzhou, $\mathrm{mg} / \mathrm{L}$

\begin{tabular}{ccccccccccc}
\hline Years & $\mathbf{S O}_{4}{ }^{2-}$ & $\mathbf{N O}_{3}{ }^{-}$ & $\mathbf{N H}_{4}{ }^{+}$ & $\mathbf{C a}^{2+}$ & $\mathbf{M g}^{2+}$ & $\mathbf{C l}^{-}$ & $\mathbf{F}^{-}$ & $\mathbf{K}^{+}$ & $\mathbf{N a}^{+}$ \\
\hline 2015 & 9.86 & 4.52 & 1.29 & 1.61 & 0.18 & 0.48 & 0.21 & 0.32 & 0.29 \\
\hline 2016 & 9.32 & 4.38 & 2.12 & 2.77 & 0.18 & 0.83 & 0.34 & 0.42 & 0.46 \\
\hline 2017 & 8.24 & 4.57 & 2.42 & 1.29 & 0.10 & 0.39 & 0.23 & 0.19 & 0.09 \\
\hline 2018 & 5.64 & 3.39 & 2.36 & 1.24 & 0.13 & 0.49 & 0.19 & 0.22 & 0.13 \\
\hline
\end{tabular}

\subsection{Ions proportion change in precipitation}

According to previous literature, precipitation is mainly dominated by sulfuric acid-type precipitation in economically underdeveloped areas. With the rapid economic development in the region, precipitation acidification will change from the previous sulfuric acid type to the mixed type of sulfuric acid and nitric acid (Mai et al., 2010). It is shown in Figure 3 that the $\mathrm{SO}_{4}{ }^{2-} / \mathrm{NO}_{3}{ }^{-}$ equivalent concentration ratio witnessed a decrease from the highest value of 4.4 in 2015 to 3.3 in 2018 .
It represents that the pollution type of acid precipitation in Luzhou city has gradually evolved from a typical sulfuric acid type to complex pollution of sulfuric acid plus nitric acid.

$\mathrm{NH}_{4}{ }^{+}$and $\mathrm{Ca}^{2+}$ are the predominant neutralization substances in rainwater, however, the neutralization by $\mathrm{Mg}^{2+}$ and $\mathrm{K}^{+}$is negligible (Hua and Han, 2011). Figure 2 shows that the equivalent concentration ratio of main cation $\mathrm{Ca}^{2+} / \mathrm{NH}_{4}{ }^{+}$, which had a neutral effect in precipitation, increased in the first two years, then declined 
from a peak of 2.5 in 2015 to 1.0 in 2018. The concentration of $\mathrm{NH}_{4}{ }^{+}$increased year by year shows that the content of $\mathrm{NH}_{3}$ in the atmosphere of Luzhou has an increasing influence on the quality of precipitation. Moreover, the only large-scale power plant around the main city completed the ammonia desulfurization technical reform project in 2015. The chemical Plant installed a selective catalytic reduction unit for denitrification treatment.

Generally, agricultural sources are regarded as the main source of $\mathrm{NH}_{3}$ emissions in the atmosphere (Kanakidou et al., 1995), (Hoek, 1998), (Aneja, 2003). Besides, related research has found that in recent years, motor vehicle exhaust and industrial emissions have become the main non-agricultural sources of $\mathrm{NH}_{3}$ in the atmosphere of urban areas (Whitehead et al., 2007), (Vollenweider, 2010). The number of cars in Luzhou city increased from 373,400 in 2015 to 568,200 in 2018 , increasing by $52.2 \%$. Also, the Chuan Nan Power Plant, a famous coal-fired power plant around the main city, completed the ammonia desulfurization technical reform project in 2015. Some Chemical Nitrification Plant in the city installed a selective catalytic reduction unit for denitrification treatment. Chuan Tian Hua, a famous large-scale chemical enterprise producing nitrocellulose, installed ammonia desulfurization in 2015 to treat $\mathrm{SO}_{2}$ emissions from the enterprise.

These treatment facilities will inevitably have an "ammonia escape" situation during use. This may be one of the reasons why the percentage of $\mathrm{NH}_{4}{ }^{+}$equivalent in precipitation in Luzhou City has increased year by year. However, the $\mathrm{NH}_{4}{ }^{+}$equivalent concentration ratio decreased slightly from 2017 to 2018 . It may be because from 2015, Luzhou City has increased the management of poultry breeding, delineated strictly banned areas and limited areas in the urban area and shut down some livestock and poultry farms that do not meet the management requirements, resulting in a decrease in $\mathrm{NH}_{3}$ emissions from agricultural sources and a decrease in the percentage of $\mathrm{NH}_{4}{ }^{+}$equivalents in precipitation.

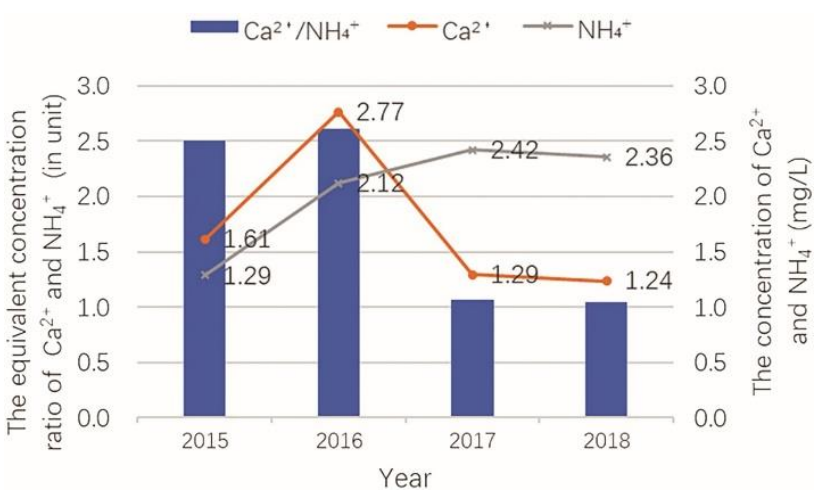

Figure 2. The equivalent concentration of $\mathrm{Ca}^{2+} / \mathrm{NH}_{4}{ }^{+}$and trend of $\mathrm{Ca}^{2+}$ and $\mathrm{NH}_{4}{ }^{+}$concentration during 2015-2018

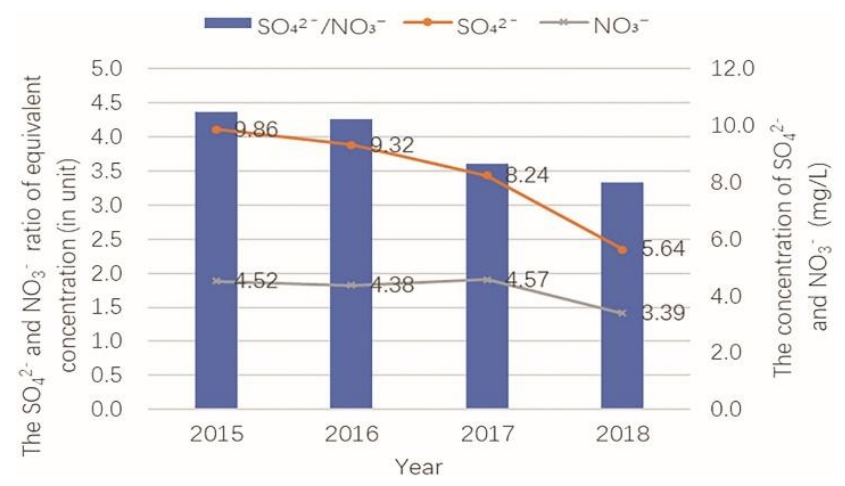

Figure 3. The equivalent concentration of $\mathrm{SO}_{4}{ }^{2-} / \mathrm{NO}_{3}{ }^{-}$and trend of $\mathrm{SO}_{4}{ }^{2-}$ and $\mathrm{NO}_{3}{ }^{-}$concentration during 2015-2018

\subsection{Trend analysis of characteristic ions in precipitation}

An in-depth analysis of the correlation between the various ion components in the precipitation can show the relationship between the ions, and it is of great benefit to determine the source of the pollutants, to understand and master the influencing factors of acid rain formation and to effectively control them (Nam et al., 2001). Pearson analysis was carried out on the correlation of ions in precipitation in Luzhou City in 2018 via SPSS software. T-test was used to ensure the significance test. The results are shown in the following Table 3.

Table 3. The correlation analysis of ions in Luzhou precipitation in 2018

\begin{tabular}{|c|c|c|c|c|c|c|c|c|c|c|}
\hline & & $\mathrm{SO}_{4}{ }^{2-}$ & $\mathrm{NO}_{3}^{-}$ & $\mathrm{F}^{-}$ & $\mathrm{Cl}^{-}$ & $\mathrm{NH}_{4}{ }^{+}$ & $\mathrm{Ca}^{2+}$ & $\mathrm{Mg}^{2+}$ & $\mathrm{Na}^{+}$ & $\mathrm{K}^{+}$ \\
\hline $\mathrm{SO}_{4}{ }^{2-}$ & Pearson & 1.000 & & & & & & & & \\
\hline $\mathrm{NO}_{3}^{-}$ & Pearson & 0.933 & 1.000 & & & & & & & \\
\hline $\mathrm{F}^{-}$ & Pearson & 0.958 & 0.902 & 1.000 & & & & & & \\
\hline $\mathrm{Cl}^{-}$ & Pearson & 0.474 & 0.420 & 0.462 & 1.000 & & & & & \\
\hline $\mathrm{NH}_{4}^{+}$ & Pearson & 0.971 & 0.911 & 0.913 & 0.568 & 1.000 & & & & \\
\hline $\mathrm{Ca}^{2+}$ & Pearson & 0.890 & 0.818 & 0.860 & 0.407 & 0.867 & 1.000 & & & \\
\hline $\mathrm{Mg}^{2+}$ & Pearson & 0.772 & 0.712 & 0.758 & 0.425 & 0.809 & 0.853 & 1.000 & & \\
\hline $\mathrm{Na}^{+}$ & Pearson & 0.176 & 0.128 & 0.158 & 0.914 & 0.304 & 0.160 & 0.283 & 1.000 & \\
\hline $\mathrm{K}^{+}$ & Pearson & 0.670 & 0.512 & 0.663 & 0.841 & 0.748 & 0.595 & 0.684 & 0.700 & 1.000 \\
\hline
\end{tabular}

Note: the correlation analysis significance level is 0.01 .

It can be seen from the data in the Table 3 that the correlation coefficient of $\mathrm{NH}_{4}{ }^{+}$with $\mathrm{SO}_{4}{ }^{2-}, \mathrm{NO}_{3}{ }^{-}$, and $\mathrm{F}^{-}$is higher in 2018, 0.971, 0.911, and 0.913, respectively.
The correlation coefficient between $\mathrm{SO}_{4}{ }^{2-}$ and $\mathrm{NO}_{3}{ }^{-}$is as high as 0.933 , which is a strong correlation between them. This may be because, during the year $2018, \mathrm{SO}_{2}$ and $\mathrm{NO}_{2}$ 
emitted by industrial enterprises entered the atmosphere together in the same way. There is also a strong correlation between $\mathrm{F}^{-}$and $\mathrm{SO}_{4}{ }^{2-}, \mathrm{NO}_{3}{ }^{-}$, which is 0.958 and 0.902 , respectively. This may be related the pollution sources such as cement and glass enterprises.

\section{Conclusion}

Based on the analysis of acid precipitation in recent four years, we can note that the Luzhou government emphasis the control of pollutant emission even though Luzhou City is in the process of high economic development. This is beneficial to society and public health. The quality improvement of acid precipitation also presented that the economic transformation of Luzhou City.

\section{Conflicts of interest}

The authors declare no conflict of interest.

\section{Acknowledgements}

This work was supported by the Scientific Research Project (17ZB0484) of Sichuan Provincial Department of Education.

\section{References}

Al-Khashman O.A. (2005), Ionic composition of wet precipitation in the Petra Region, Jordan, Atmospheric Research, 78, 0-12.

Aneja V.P. (2003), Agricultural ammonia emissions and ammonium concentrations associated with aerosols and precipitation in the southeast United States, Journal of Geophysical Research, 108, 4152.

Bowman C.T. (1992), Control of combustion-generated nitrogen oxide emissions: technology driven by regulation, Symposium on Combustion, 24, 859-878.

Charlson R.J. and Rodhe H. (1982), Factors controlling the acidity of natural rainwater, Nature, 295, 683-685.

Galloway J.N., Likens G.E. and Edgerton E.S. (1976), Acid Precipitation in the Northeastern United States: $\mathrm{pH}$ and Acidity, Science, 194, 722-724.

Galloway J.N., Savoie D.L., Keene W.C. and Prospero J.M. (1993), The temporal and spatial variability of scavenging ratios for NSS sulfate, nitrate, methanesulfonate and sodium in the Atmosphere over the North Atalantic Ocean, Atmospheric Environment. Part A. General Topics, 27, 235-250.

Gao S., Sakamoto K. and Zhao D. (2001), Studies on Stmospheric pollution, acid rain and Emission control for their precursors in Chongqing, China, Water, Air, and Soil Pollution, 130, 247252.

Grimm J.W. and Lynch J.A. (2004), Enhanced Wet Deposition Estimates using Modeled Precipitation Inputs, Environmental Monitoring Assessment, 90, 243-268.

Hoek K.W.V.D. (1998), Estimating ammonia emission factors in Europe: summary of the work of the UNECE ammonia expert panel, Atmospheric Environment, 32, 315-316.

Hua W. and Han G. (2011), Chemical composition of rainwater and anthropogenic influences in Chengdu, Southwest China, Atmospheric Research, 99, 0-196.

Kanakidou M., Dentener F.J. and Crutzen P.J. (1995), A global three-dimensional study of the fate of HCFCs and HFC-134a in the troposphere, Journal of Geophysical Research Atmospheres, 100, 18781-18801.
Lin N.-H., Lee H.-M. and Chang M.-B. (1999), Evaluation of the characteristics of acid precipitation in taipei, taiwan using cluster analysis, Water Air \& Soil Pollution, 113, 241-260.

Mai B.R., Zheng Y.F., Rong-Jun W.U. and Liang J.J.C.J.o.P.E. (2010), Effects of simulated sulfur-rich, nitric-rich and mixed acid rain on the physiology, growth and yield of rape (Brassica napus).

Menz F.C. and Seip H.M. (2004), Acid rain in Europe and the United States: an update, Environmental Science \& Policy, 7, 253-265.

Mutahharah M.M., Mimi H.H. and Rozainee T.M. (2014), Health risk assessment of emissions from a coal-fired power plant using AERMOD modelling, Process Safety and Environmental Protection.

Nam J.C., Oh S.-N., Choi J.-C., Kim J. and Chun Y. (2001), Monitoring of Acid Rain over Korean Peninsula, Water, Air, and Soil Pollution, 130, 433-438.

Shi C.E., Deng X.L., Wu B.W., Hong J., Zhang S. and Yang Y.J. (2013), Characteristics of precipitation $\mathrm{pH}$ and conductivity at $\mathrm{Mt}$. Huang, Environmental Science, 34, 1964.

Siddiqi S.A. and Farsi B.A. (2019), The Contribution of Greenhouse Gas Emissions on Future Acid Rain in States of Gulf Cooperation Council: Measures to Adopt, Journal of Geoscience Environment Protection, 82-98.

US EPA (2017a), Air Pollution: Current and Future Challenges.

Vollenweider X. (2010), Ammonia emissions from UK nonagricultural sources in 2008: contribution to the National Atmospheric Emission Inventory, Nerc/centre for Ecology \& Hydrology.

Wakida S.I., Yamane M., Takeda S., Siroma Z., Tsujimura Y. and Liu J. (2001), Studies on pH and Nitrate Checkers Made of Semiconductor Devices for Acid Rain Monitoring, Water, Air, \& Soil Pollution, 130, 625-630.

Whitehead J.D., Longley I.D. and Gallagher M.W. (2007), Seasonal and Diurnal Variation in Atmospheric Ammonia in an Urban Environment Measured Using a Quantum Cascade Laser Absorption Spectrometer, Water Air \& Soil Pollution, 183, 317-329.

Wisniewski J. and Kinsman J.D. (1988), pH and hydrogen ion deposition patterns in precipitation for the continental United States and Canada, Water Air Soil Pollution, 38, 1-17. 